\title{
Research on the Long-term Mechanism of Energy Reduction
}

\author{
Ronglan $\mathrm{He}$ \\ School of Management, Northwest University for Nationalities, Lanzhou (730124), P.R. China \\ 107712708@qq.com
}

Keywords: Energy reduction; Long-term mechanism; Power source; Operability.

\begin{abstract}
Since the foundation of energy reduction's long-term mechanism has already been made. This thesis mainly focus on energy reduction's long-term mechanism's contents and its inside relationships, and proposes some operable strategies on energy reduction area.
\end{abstract}

\section{Introduction}

As energy shortage, severe pollution problem, energy conservation and emissions reduction for the nation's energy security, environmental protection and sustainable economic and social development has far-reaching significance. How to bear ability, on the basis of considering economic development step by step, by stages to reduce energy consumption, environmental governance is the world's common problems. In today's our country proposed the request of the sustainable economic development model, to establish a long-term mechanism for energy conservation and emissions reduction, economic development is to solve the energy problem and environment problem of the key is used to raise the inevitable requirement of economic growth mode.

\section{The Theoretical and Practical Basis of A Long-term Mechanism}

A long-term mechanism is not once and for all, remains the same, it must be as the change of time, conditions, and constantly enrich and develop and perfect. Understand the long-term mechanism, from the "long", "mechanism" to grasp two key words. Mechanism is to make the system to normal operation and the expected functions of supporting system. It has two basic conditions: one is to want to have more specifications, stability, supporting system; second, must have driven system normal operation of the "power", which should have for their own interests to actively promote and supervise the system operation of the organization and individuals. "Long-term", excluding short-term behavior and lack of persistent driving force supporting system, emphasizes the system lasting contact closely with the interests of the organization and individual, able to form a stable "power source". Visible, the establishment of long-term mechanism need to be in energy saving and emission reduction system and the content of the system operational aspects of an in-depth study and find a stimulus related subject interests, to promote the effect of energy conservation and emissions reduction system innovation breakthrough. On this basis, relying on economic policy and environmental regulation and policy guidance, the use of policy and legal system can adjust stability, lasting and improve our market economic benefit, social benefit and environmental ecological benefits of the comprehensive coordination level, and realize the sustainable development of in the true sense.

From China during the period of "11th five-year plan" energy conservation and emissions reduction, the practice of some places in closer to the time limit to take electricity targets such as extreme way, exposed the flaws in the system of energy conservation and emissions reduction a lack of long-term system effect, it is imperative to build a long-term mechanism of system about energy conservation and emissions tackling both the symptoms. reduction in China, the basic system has been formed, the government has started to use economic means, legal means and administrative means, a comprehensive adjustment of energy conservation and emissions reduction activities but due to the imperfect mechanism, this system lack of momentum and persistent binding, operability is poor, difficult to achieve the function of the expected value. 
At present, the implementation of energy conservation and emissions reduction, has the long-term mechanism:

The system foundation has been laid. at present our country combination adjustment of the energy conservation and emissions reduction laws and regulations system basic formation. The energy conservation law of the People's Republic of China in the form of law clear the "energy conservation is a long-term concept of strategy of national economic development", provides legal guarantee for China's energy saving actions. Laws and regulations is a powerful means of implementation of the basic law, in the aspect of corporate responsibility, government responsibility, social responsibility to build a relatively complete system of responsibility, energy conservation, emission reduction, control, governance and development of the comprehensive adjustment system, involving the industry adjustment, fiscal taxation, finance, content of pollution charge price system, etc.[2]

Basic clear to long-term mechanism framework. According to the current content of energy conservation and emissions reduction mechanism study, a long-term mechanism mainly includes the development guide mechanism, the incentive constraints mechanism, evaluation mechanism, enterprise mechanism and social linkages mechanism, etc.

Development direction mechanism: namely play a guiding role in energy conservation and emission reduction system in the economic and social development. Main ways: reflect national energy conservation and emissions reduction policy intentions, strengthen the government, enterprises, social responsibility consciousness, energy saving and emission reduction will be incorporated into the national economic and social development goals.

Incentive constraint mechanism: namely through fiscal, tax, financial and other economic means to promote energy conservation and emissions reduction behavior, constraints and punishment for the violation of energy conservation and emissions reduction behavior. Main ways: To improve energy conservation and environmental protection investment, lower production costs, energy conservation and environmental protection for environmental resources regional compensation system, to punish illegal behavior.

Evaluation mechanism: the effect of energy conservation and emission reduction should be a scientific calculation method and evaluation system. Main ways: set up a comprehensive and reasonable assessment standard, the gradual objective evaluation.

Enterprise incentive mechanism: namely, to establish measures to enhance the enthusiasm of the enterprise energy conservation and emissions reduction system. Main ways: government "the visible hand" to the enterprise to carry on the economic support, produce the inner motive power of enterprise energy conservation and emissions reduction; Using the "invisible hand" of market resources based configuration, enterprise energy conservation and emissions reduction of external pressure.

Social linkages mechanism: namely, mobilize social forces, promote the implementation of energy saving and emission reduction. Main ways: strengthen energy conservation and emissions reduction propaganda education, improve the whole society's awareness of energy conservation and environmental protection, strength the administration according to law intensify supervision.

The content of the long-term mechanism

In the real conditions for it has been under the premise of the normal operation of the long-term mechanism for energy conservation and emissions reduction requires two key factors: one is the "power source", the second is the "power source" of persistent effect.

Looking for excitation system of "power". "Power supply" is out of self-interest and actively promotes and supervises the system operation of the organization and individuals. According to the individual behavior motivation theories of management psychology, people's behavior motives mainly is decided by two factors, namely the consciousness of internal and external environment, thus derived two models: motive expectation model and tooling model. Usually, people always use these two kinds of models to explain respectively decided to power, people's behavior motives tend to ignore common characteristics: two models is a reflection of the behavior motive stimulation and satisfaction forever the self-interest of the agent has the positive correlation. Whether internal or 
external environment consciousness, total want to through consideration of human nature - the "interests" to processing a variety of factors and give up, so as to guide people's behavior. However, the "interest" of man is not the simple often include economic interests, social interests and other interests. Artificial main body, at the beginning of its establishment in the interests of the often have a clear goal, for example, enterprise's goal is to achieve maximum economic benefits, and state administrative organs of the goal is to realize the maximization of social benefits. This simplified to some extent this kind of main body of the behavior motive, makes the factors that motivate them relative to a single, more complicated than the excitation of individual behavior is more simple and clear. As the body of the implementation of energy conservation and emissions reduction, enterprise's primary goal is the realization of the interests of the economy. In effect under the premise of economic interests, enterprise will not produce the impulse to energy saving and emission reduction. According to this train of thought, to make the enterprise become a true "power source", energy saving and emission reduction is the only way to energy conservation and emissions reduction can really bring the interests of the enterprise must, so that enterprises can truly push and monitor the operation of the system of energy conservation and emissions reduction. How to energy-saving emission reduction to business interests? The establishment of the incentive mechanism is the response to this problem. First, the government economic support to the enterprise, reduce the cost of energy conservation and emissions reduction, and make the enterprise see long-term benefits of energy conservation and emissions reduction, achieve the anticipated goal of circular economy. Second, through the market allocation of resources, makes the energy conservation and emissions reduction benefit main body, the external pressure of market competition, arouse the enthusiasm of enterprise's energy conservation and emissions reduction. Internal system itself also needs to coordinate the dynamic mechanism, the government's support to achieve reasonable limits, to make enterprise see hope and not become dependent, both at the same time, the market competition environment will play the role of optimizing resource allocation, can really form evolution to the enterprise pressure, under the dual role, "power source" can be stimulated.

The establishment of a lasting "power source" system. Enterprise's incentive mechanism is the "power" of the core system. Set up this mechanism, however, may not be able to make the enterprise be persistent excitation, need a series of auxiliary mechanism to cooperate. According to the framework of a long-term mechanism for energy conservation and emissions reduction, and other mechanisms are built around enterprise motivation mechanism, and have the lasting auxiliary effect. Development guiding mechanism from the macroeconomic policy guidance, incentive constraint mechanism stimulated from the rewards and punishment method, evaluation mechanism evaluation from quality, social linkage mechanism, supervision and encouragement from the viewpoint of society as a whole. Thus, it can be seen that enterprise's behavior is not isolated, energy saving and emission reduction needs government, market and society's full support and cooperation. Lasting energy saving and emission reduction mechanism of government transformation is an important functional role, public service as the main function; Have strong request for market function, improve the stability of the market order is the foundation of enterprise development environment; Social supervision and support of the masses to promote enterprise the smooth implementation of energy saving and emission reduction. Lasting "power source" system is a system engineering, need government, market and society function of independence and subject itself is perfect, at present, it is because of all sorts of main body function dislocation or does not reach the designated position, restricted the energy conservation and emissions reduction mechanism of lasting effect.

\section{Improve the Maneuverability of the Long-term Mechanism}

In order to improve the maneuverability of the long-term mechanism, in addition to improve the maneuverability of the system itself, but also pay attention to the cooperation and coordination between the systems.

The maneuverability of the system itself. As the core system of long-term mechanism for energy 
conservation and emissions reduction, enterprise motivation mechanism of the running, of course, inseparable from the government and the stimulation of market, but the establishment and perfection of system of enterprise itself is an important factor of motivation mechanisms to function. Enterprises to establish a special management institution, energy saving and emission reduction is responsible for the planning, organization, command, control and coordination work, prepare a list of the detailed work tasks and work process, standard quantitative work, strengthen the enterprise internal assessment and evaluation of energy conservation and emissions reduction behavior, finally carries on the continuous feedback and innovation, so as to improve the maneuverability of the system. Improving other auxiliary system operability involving government, market and social efficiency of the play and the enhancement, the key is to straighten out the government, market and social functions, fostering their development space, using legal norms at the same time, to prevent improper interference between each other.

The coordination and cooperation between the 2 system. For now, and perfecting the government, enterprise, market and social function is the primary problem, on this basis, the coordination between the various system, should be considered separately from the main body should be the balance of interests, the means of cooperation, target unity, resource sharing and integration of several aspects such as coordination of measures, the core is to reduce the contradiction between institutions, improve the fluency of the system operation.

\section{Conclusions}

A long-term mechanism for energy conservation and emissions reduction system is a system, the system of the elements surrounding the enterprise incentive mechanism, the core of the system involves the main body to strengthening its function, and in the interests of the goals, means and realize the effective connection, resources, etc. The institutional system as shown in the figure below:

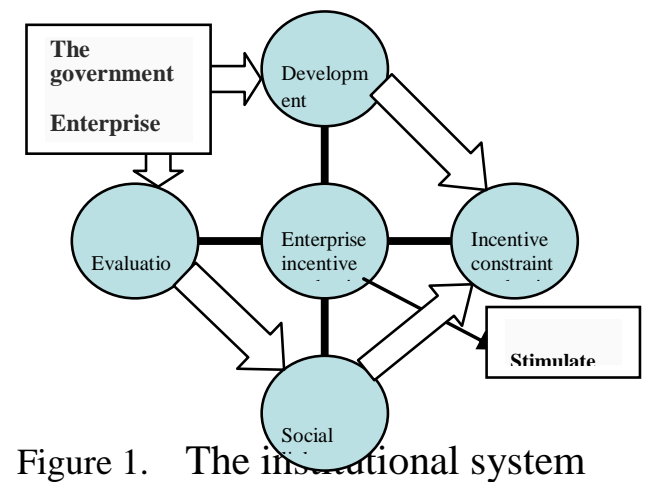

\section{Acknowledgements}

This work was supported by the Fundamental Research Funds for the Central Universities of Northwest University for Nationalities (grant No. 31920130090).

\section{References}

[1] Aimin Zhang: The consideration of the government guarantee legal system energy saving and emission reduction $[\mathrm{J}]$, The rule of law and society,2010 (7) (on).

[2] Ronglan He: On the evolution of our law system of energy conservation and emissions reduction and improve [J],The rule of law and society,2011 (8).

[3] Zhongying Sun: To establish a long-term mechanism for energy conservation and emissions reduction research[J],Cutting edge,2010 (3).

[4] Kaufmann R.K., The Mechanisms for Autonomous Energy Efficiency Increases: A Co integration Analysis of the US Energy/GDP Ratio [J], The Energy Journal, 2004.25.

[5] Fisher-Vanden K,Gary H.Jefferson, Hongmei Liu and etc. What is Driving China's Decline in 
Energy Intensity [J], Resource and Energy Economics, 2004.26.

[6] S.Murillo, J.L.Míguez, J.Porteiro and etc. Viability of LPG use in low-power outboard engines for reduction in consumption and pollutant emissions[J], International Journal of Energy Research,2003 Vol.33, No.5, pp.467-480.

[7] Wang Xiaojie, Zhou Yingnan, Liu Huanhuan. Research on the Forecasting Model of Energy-saving Potentials in Industry Enterprises. China Population, Resources and Environment [J]. 2010, Vol.20, No.5, pp.27-30.

[8] $\mathrm{Hu}$ Shuhua. Weighting Comprehensive Evaluation Method and Its Applications for Product Design Evaluation. China Mechanical Engineering [J].1993 (11), pp.26-29.

[9] Richard G.Newell, AdamB.Jaffe, Robert N.Stavins.The effect of economic and policy incentives on carbon mitigation technologies [J], Energy Economics, 2006.11.563-578.

[10]Wang Yafei, Zheng Minghui. "Allocation of Energy Consumption among Provinces in China and Energy Saving Analysis", Guizhou Agricultural Science [J]. 2012, Vol.40, No.5, pp.195-200.

[11]Wu Peilin,Wang Jianjun,Wang Hua. "Energy Conservation Potential Analysis in Compressed Air System for Industry Enterprises”. Compessor Technology [J]. 2012, No.1, pp.38-40. 